удК 631.16: 336.2(571.54)

И. Ц. Доржиева

Бурятская государственная сельскохозяйственная академия им. В. Р. Филиппова, г. Улан-Удэ, Российская Федеращия

С. В. Гомбожапова

Бурятская государственная сельскохозяйственная академия им. В. Р. Филиппова, г. Улан-Удэ, Российская Федерация

И. Т. Данеева

Байкальский государственный университет, г. Иркутск, Российская Федерация

\title{
ОСОБЕННОСТИ НАЛОГООБЛОЖКЕНИЯ СЕЛЬСКОХОЗЯЙСТВЕННЫХ ТОВАРОПРОИЗВОДИТЕЛЕЙ РЕСПУБЛИКИ БУРЯТИЯ
}

\begin{abstract}
АНнотАЦия. Сельское хозяйство является стратегически важным и основополагающим сектором экономики любого государства. Уровень продовольственной независимости страны зависит от того, насколько развито сельскохозяйственное производство. В современных условиях особое внимание уделяется вопросам налогообложения производителей данного сектора, которое имеет ряд особенностей. В статье оценивается степень влияния системы налогообложения на экономическое положение сельскохозяйственных товаропроизводителей в рассматриваемом регионе, анализируется уровень налоговой нагрузки сельхозтоваропроизводителей и факторы, оказывающие влияние на значение данного показателя. $\mathrm{K}$ таким факторам, в частности, относятся структурный анализ налоговых поступлений, показатель совокупной налоговой задолженности, применение специального режима налогообложения. Приводятся недостатки и преимущества льготного режима обложения и направления совершенствования существующей системы обложения сельхозтоваропроизводителей.

КЛЮЧЕВЫЕ СЛОВА. Налогообложение сельскохозяйственных товаропроизводителей; налоговая нагрузка; структура налоговых платежей; налоговая задолженность; специальный режим налогообложения, единый сельскохозяйственный налог.

ИНФОРМАЦИЯ О СТАТЬЕ. Дата поступления 15 октября 2016 г.; дата принятия к печати 27 октября 2016 г.; дата онлайн-размещения 30 ноября 2016 г.
\end{abstract}

I. Ts. Dorzhiyeva

V. R. Filippov Buryat State Agricultural Academy, Ulan-Ude, Russian Federation

S. V. Gombozhapova

V. R. Filippov Buryat State Agricultural Academy, Ulan-Ude, Russian Federation

I. T. Daneyeva Baikal State University, Irkutsk, Russian Federation

\section{TAXATION FEATURES FOR AGRICULTURAL COMMODITY PRODUCERS IN REPUBLIC OF BURYATIA}

ABSTRACT. Agriculture is a strategically significant fundamental and essential sector of any country's economy. The food independence level of a country depends on the level of its agricultural development. In the current context, particular attention is given to issues of producers taxation in this sector which has a number of specific features. The article evaluates the degree of the tax system influence on economic situation of agricultural commodity producers in the region under consideration, analyses the level of their tax burden and the factors that influence the value of this indicator. These factors include, in particular, a structural analysis of tax revenue, an aggregate

\section{Baikal Research Journal}


tax liabilities indicator, use of special tax treatment. The article also brings forth the advantages and disadvantages of the preferential tax treatment and directions of improving the existing tax system for agricultural commodity producers.

KEYWORDS. Taxation of agricultural commodity producers; tax burden; tax payment structure; tax liability; special tax treatment; unified agricultural tax.

ARTICLE INFO. Received October 15, 2016; accepted October 27, 2016; available online November 30, 2016.

Сельское хозяйство Республики Бурятия обеспечивает значительную часть занятости в регионе и является многоотраслевой системой, в которой создается до $10 \%$ валового регионального продукта. Стоимость продукции отрасли в 2014 г. достигла 16731 млн р., наблюдается ежегодный рост производства продукции в течение 2006-2014 гг. Индекс физического объема производства продукции сельского хозяйства держится на уровне свыше $100 \%$, но не превышает в целом $103 \%$, что свидетельствует об увеличении объемов производства небольшими темпами. Производство продукции сельского хозяйства на душу населения в 2014 г. по отношению к 2006 г. снизилось на $15 \%$ [1, с. 142].

Отрасль сельского хозяйства в некоторых регионах Сибирского федерального округа, включая Бурятию, характеризуется низким уровнем рентабельности, недостаточным государственным финансированием, неудовлетворительным состоянием производственных фондов, слабым развитием социальной инфраструктуры и др. [2, с. 113].

Развитие сельского хозяйства страны, обеспечивающего производство продуктов питания и сырья для промышленности, во многом зависит от налогового регулирования [3, с. 32]. Поэтому проблема налогообложения сельскохозяйственных товаропроизводителей имеет особую актуальность. Налогообложение предприятий рассматривают многие отечественные исследователи, например, А. П. Киреенко, В. И. Самаруха, А. Д. Шеремет, В. Г. Пансков, Е. Ф. Киреева и др. Однако региональный и отраслевой аспект данной проблемы еще недостаточно изучен.

Проведем оценку воздействия существующей системы налогообложения на экономическое положение сельскохозяйственных товаропроизводителей Республики Бурятия. Налоги представляют собой изъятие определенной доли финансовых ресурсов хозяйствующих субъектов и отражают закономерности показателей их деятельности как часть распределительных отношений общества [4]. В масштабах региона, на наш взгляд, целесообразно использовать показатель уровня налоговых изъятий, рассчитанный как отношение налоговых платежей по отрасли к величине валовой продукции сельского хозяйства (табл. 1).

Существенного снижения уровня налоговой нагрузки на сельскохозяйственных товаропроизводителей региона в течение рассматриваемого периода не наблюдается. Вместе с тем, соотношение суммы налоговых платежей с валовой продукцией сельского хозяйства выявило определенное расхождение уровня налоговых изъятий в течение рассматриваемого периода. Так, в 2006-2008 гг. показатель налоговых изъятий по отрасли равен 0,6-0,7 \%, а в 2009-2011 гг. - варьирует в пределах от 1,1 до $1,5 \%$.

Увеличение уровня налоговой нагрузки отрицательно сказывается на экономических показателях, характеризующих отрасль, и не способствует наращению налогооблагаемой базы.

Также в течение 2012 и 2013 гг. наблюдается возмещение налоговых платежей из бюджета в размере 65,9 и 111,2 млн р. соответственно.

Структурный анализ налоговых платежей позволил выявить следующее: в течение 2012 и 2013 гг. сумма НДС к возмещению из бюджета составила 178001 тыс. р. и 215556 тыс. р. соответственно. Объясняется это тем, что в

\section{Baikal Research Journal}

электронный научный журнал Байкальского государственного университета 
рамках республиканской целевой программы, финансируемой за счет средств федерального бюджета, агролизинговой компанией были приобретены дорогостоящие высокотехнологические оборудования и машины. Учитывая экономическую природу налога на добавленную стоимость вычету (возмещению) подлежит сумма «входного» налога по приобретенным товарам (работам, услугам).

Диналика доли налоговых платежей по отрасли (без учета обязательных 1 страховых взносов) в валовой продукции сельского хозяйства

в хозяйствах всех категорий по Республике Бурятия за 2006-2014 г2.

\begin{tabular}{|r|r|r|rr|}
\hline Годы & $\begin{array}{c}\text { Валовая продукция } \\
\text { сельского хозяйства, } \\
\text { млн р. }\end{array}$ & $\begin{array}{c}\text { Поступило налоговых } \\
\text { платежей по отрасли, } \\
\text { тыс. р. }\end{array}$ & \multicolumn{2}{|c|}{$\begin{array}{c}\text { Доля налоговых платежей по } \\
\text { отрасли в валовой продукции } \\
\text { сельского хозяйства, \% }\end{array}$} \\
\hline 2006 & 8994 & 56657 & 0,6 \\
\hline 2007 & 10546 & 62704 & 0,6 \\
\hline 2008 & 11746 & 86397 & 0,7 \\
\hline 2009 & 12086 & 130074 & 1,1 \\
\hline 2010 & 10602 & 162064 & 1,5 \\
\hline 2011 & 13044 & 160835 & $-0,5$ \\
\hline 2012 & 13684 & -65883 & $-0,8$ \\
\hline 2013 & 14199 & -111242 & 0,7 \\
\hline 2014 & 16731 & 109427 & \\
\hline
\end{tabular}

Составлено по данным формы налоговой отчетности 1-НОМ «О поступлении налогов и сборов в консолидированный бюджет Российской Федерации по основным видам экономической деятельности» Управления федеральной налоговой службы по Республике Бурятия за соответствующие годы.

На динамику налоговых поступлений влияет не только уплата текущих платежей, но и сумма задолженности налогоплательщиков перед бюджетом. Фактические поступления налогов могут либо превосходить начисленные к уплате суммы вследствие погашения задолженности прошлых лет, либо быть ниже начисленных сумм по причине текущей неплатежеспособности налогоплательщиков. $K$ тому же, не исключены и переплаты вследствие ошибок в исчислении суммы налога или неправильного проведения суммы платежа [5, с. 75].

Рассмотрим показатель налоговой задолженности по отрасли в динамике за исследуемый период (табл. 2).

Динамика доли налоговой задолженности в общей сумме

Таблица 2 налоговых поступлений (без учета обязательных страховых взносов) по отрасли сельского хозяйства в Республике Бурятия за 2006-2014 22.

\begin{tabular}{|c|r|r|r|}
\hline Годы & $\begin{array}{c}\text { Задолженность } \\
\text { по налогам и сборам } \\
\text { по отрасли, тыс. p. }\end{array}$ & $\begin{array}{c}\text { Поступило налоговых } \\
\text { платежей по отрасли, } \\
\text { тыс. р. }\end{array}$ & $\begin{array}{l}\text { Доля задолженности по налогам } \\
\text { и сборам в налоговых } \\
\text { поступлениях по отрасли, \% }\end{array}$ \\
\hline 2006 & 47509 & 56657 & 83,9 \\
\hline 2007 & 17392 & 62704 & 27,7 \\
\hline 2008 & 17414 & 86397 & 20,2 \\
\hline 2009 & 15607 & 130074 & 12,0 \\
\hline 2010 & 15976 & 162064 & 9,9 \\
\hline 2011 & 17251 & 160835 & 10,7 \\
\hline 2012 & 14607 & -65883 & $-22,2$ \\
\hline 2013 & 38251 & -111242 & $-34,4$ \\
\hline 2014 & 26250 & 109427 & 24,0 \\
\hline
\end{tabular}

Составлено по данным формы налоговой отчетности 4-НОМ «О задолженности по налогам и сборам, пеням и налоговым санкциям в бюджетную систему Российской Федерации по основным видам экономической деятельности» и 1 -HOM «О поступлении налогов и сборов в консолидированный бюджет РФ по основным видам экономической деятельности" Управления федеральной налоговой службы по Республике Бурятия за соответствующие годы.

\section{Baikal Research Journal}

электронный научный журнал Байкальского государственного университета 
С улучшением общей экономической ситуации в стране до начала финансового кризиса отмечается снижение абсолютной суммы задолженности сельхозтоваропроизводителей. При анализе динамики налоговых поступлений по отрасли это порождает противоречие, в связи с чем поступления в счет погашения задолженности по налогам и сборам рекомендуем выделять отдельной строкой.

Задолженность по налогам, сборам, пеням и налоговым санкциям (далее совокупная налоговая задолженность) в целом по отрасли по состоянию на 1 января 2015 г. достигла 26250 тыс. р., что составляет $24 \%$ от величины поступивших налоговых доходов с территории региона.

На протяжении рассматриваемого периода доля совокупной налоговой задолженности в фактических налоговых поступлениях по отрасли существенно снизилась: с 83,9 до 24,0 \%. Рост задолженности по налогам и сборам в 2013 г. до 38251 тыс. р. явился прямым следствием кризисных явлений в экономике, связанным со снижением ликвидности и платежеспособности организаций.

К числу особенностей налогообложения в сельском хозяйстве относятся наличие льготного порядка взимания налогов и сборов, применение единого налога [6, с. 98].

Одним из наиболее актуальных механизмов налогового регулирования аграрного сектора выступает обоснованность применения специального режима налогообложения сельхозтоваропроизводителей в виде уплаты единого сельскохозяйственного налога (ECXH). При переходе на уплату ECXH уровень налоговой нагрузки конкретного хозяйствующего субъекта заметно уменьшается [7, с. 75]. Сокращение налоговых платежей позволяет снижать расходы организации и стабилизировать ее финансовое положение. Кроме того, уплата ЕСХН позволяет сократить объемы налоговых расчетов и отчетности [8, с. 65].

Рассмотрим особенности общего и специального льготного режимов налогообложения сельскохозяйственных товаропроизводителей. Структура и состав обязательных платежей, уплачиваемых сельскохозяйственными товаропроизводителями, по двум различным режимам налогообложения представлен на рисунке.

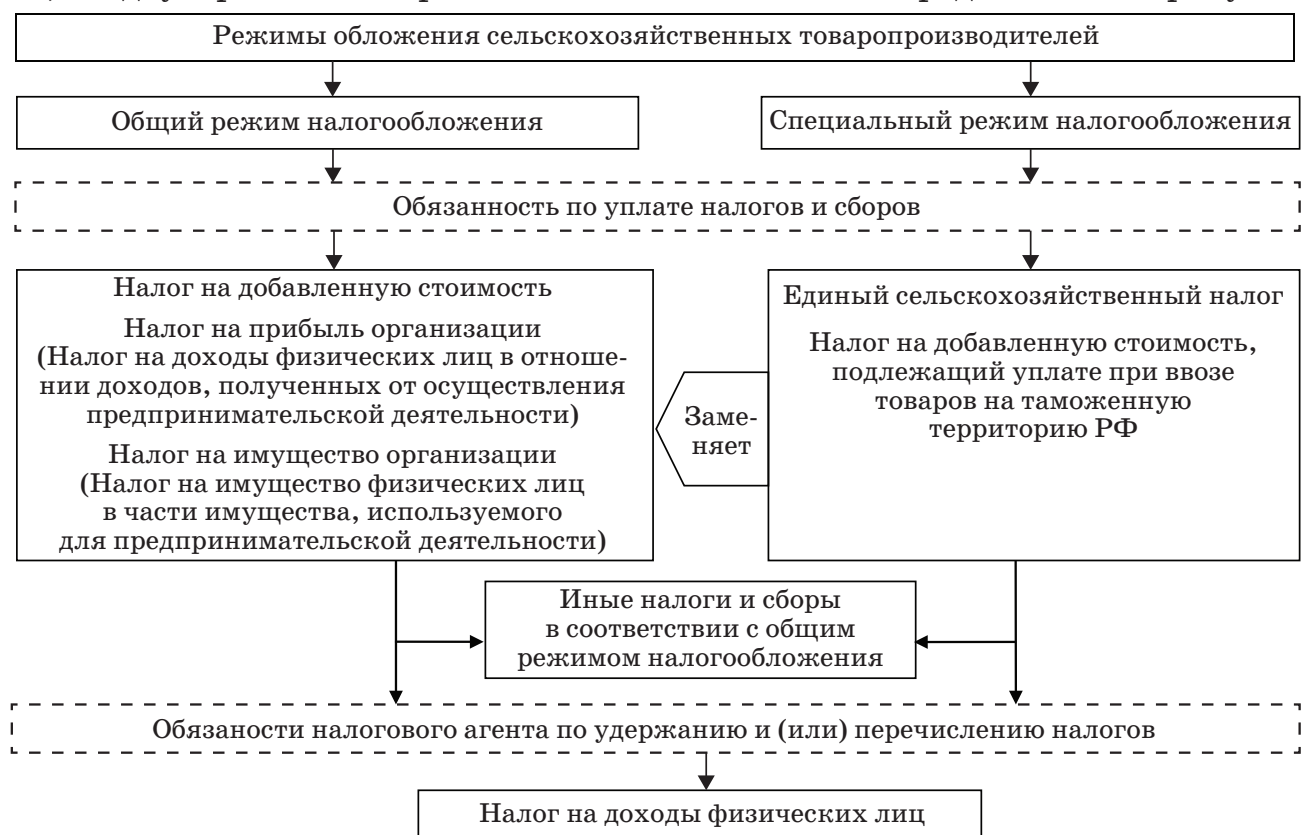

Общий и специальный режилы обложения сельскохозяйственных товаропроизводителей

\section{Baikal Research Journal}


Согласно рисунку переход на единый сельскохозяйственный налог предусматривает замену уплаты ряда налогов уплатой единого налога, исчисляемого по результатам хозяйственной деятельности за налоговый период. Иные налоги и сборы уплачиваются организациями и индивидуальными предпринимателями в соответствии с общим режимом налогообложения.

Неблагоприятными последствиями применения специального режима налогообложения является освобождение от уплаты НДС. Несмотря на то, что это позволяет снизить налоговую нагрузку плательщиков, освобождение от уплаты НДС приводит к увеличению затрат на сумму данного налога по приобретаемым материальным ценностям (работам, услугам). Следовательно, ведет к увеличению стоимости товарной продукции. Отсутствие обязательств по исчислению и уплате НДС приводит и к лишению прав на вычет этого налога [9, с. 56].

К тому же, освобождение от уплаты НДС отчасти затрудняет сотрудничество сельскохозяйственных товаропроизводителей с контрагентами находящимися на общем режиме налогообложения [10, с. 27].

В настоящее время в научных кругах и на законодательном уровне рассматривается возможность плательщиков ЕСХН одновременно являться и плательщиками НДС. Причем положительный эффект от нововведения для бюджета уже подсчитан. По расчетам Минсельхоза России, произведенным по данным отчетности Федеральной налоговой службы России за 2015 г., бюджет может получить дополнительно за счет уплаты НДС до 26,6 млрд.$^{1}$ Речь, так полагаем, идет о не предоставлении возможности хозяйствующим субъектам права самостоятельного выбора наиболее выгодного режима обложения, а об обязательстве по уплате НДС.

Такой подход, может негативно повлиять на финансовое положение сельхозтовапроизводителей, не отвечает требованиям оптимизации налоговой нагрузки и может привести, в конечном итоге, к сокращению объемов налоговых поступлений по отрасли. $К$ тому же, для значительной части средних и мелких сельхозтовапроизводителей это приведет к серьезному усложнению бухгалтерского учета. И дополнительные издержки, которые они с этим понесут, плюсов от перехода на уплату НДС не перекроют.

Практика применения единого налога в течение анализируемого периода выявила неспособность значительной части сельскохозяйственных производителей использовать специальный налоговый режим (табл. 3).

Доля налоговых платежей сельхозтоваропроизводителей, применяющих специальный режим налогообложения занимает в среднем менее $1 / 5$ части общей суммы налоговых платежей.

Существенным ограничением для перехода на специальный налоговый режим является выполнение необходимого критерия - доля доходов от реализации сельскохозяйственной продукции собственного производства должна составлять более $70 \%$ от общей суммы доходов. Следовательно, специальный режим налогообложения применим мелкими и средними сельхозтоваропроизводителями. Расширение производства и дальнейшая первичная и промышленная переработка продукции, экономически целесообразные при существующем диспаритете цен, приводят к утрате права на применение льготного режима обложения [11, с. 42].

Разработка направлений совершенствования применения ЕСХН должна учитывать специфические особенности хозяйствования в аграрном секторе, к которым относятся сезонный характер производства и зависимость от природно-климатических условий, наличие диспаритета цен на продукцию сельского хозяйства и промышленности, финансово-экономическое состояние сельскохозяйственных производителей и др. [12, с. 39].

${ }^{1}$ URL: https://rg.ru/2016/08/22/fermeram-dadut-pravo-dobrovolno-platit-nds.html.

\section{Baikal Research Journal}

электронный научный журнал Байкальского государственного университета 
Таблица 3

Диналика доли налоговых поступлений от применения специальных режилов налогообложения в обшей сулле налоговых поступлений

(без учета обязательных страховых взносов) по отрасли сельского хозяйства в Республике Бурятия за 2006-2014 г2.

\begin{tabular}{|r|r|r|r|}
\hline Годы & $\begin{array}{c}\text { Поступило налоговых платежей } \\
\text { от применения специальных } \\
\text { режимом налогообложения, } \\
\text { тыс. p. }\end{array}$ & $\begin{array}{c}\text { Поступило налоговых } \\
\text { платежей по отрас- } \\
\text { ли всего, тыс. } \mathbf{p} .\end{array}$ & $\begin{array}{c}\text { Доля поступлений от примене- } \\
\text { ния специальных режимов в } \\
\text { общей сумме налоговых посту- } \\
\text { плений, \% }\end{array}$ \\
\hline 2006 & 5829 & 56657 & 10,3 \\
\hline 2007 & 10718 & 62704 & 17,1 \\
\hline 2008 & 13134 & 86397 & 15,2 \\
\hline 2009 & 11404 & 130074 & 8,8 \\
\hline 2010 & 17348 & 162064 & 10,7 \\
\hline 2011 & 22898 & 160835 & 14,2 \\
\hline 2012 & 20464 & -65883 & $-31,1$ \\
\hline 2013 & 20045 & -111242 & $-18,0$ \\
\hline 2014 & 22954 & 109427 & 21,0 \\
\hline
\end{tabular}

Составлено по данным формы налоговой отчетности 1-НОМ «О поступлении налогов и сборов в консолидированный бюджет Российской Федерации по основным видам экономической деятельности" Управления федеральной налоговой службы по субъектам Сибирского федерального округа за соответствующие годы.

Таким образом, можно сделать следующие выводы:

1. Необходимо смещение основного акцента с позиций кратковременных фискальных интересов к стимулированию роста производства с дальнейшей перспективой повышения объема налоговых платежей. На уровень налоговой нагрузки сельхозтовапроизводителей существенную роль оказывают показатель налоговой задолженности и сумма инвестиций в обновление основных фондов сельского хозяйства, сводящаяся к возмещению «входного» НДС по приобретенным основным средствам.

2. Практика применения специального режима обложения сельхозтоваропроизводителями выявила неспособность значительной части сельскохозяйственных производителей использовать специальный налоговый режим. Применение специального режима обложения является более выгодным для использования мелкими и средними сельскохозяйственными товаропроизводителями. Крупные сельскохозяйственные организации редко соответствуют критерию применения ECXН, поскольку их деятельность не является строго специализированной, для таких организаций свойственна диверсификация деятельности.

3. Установление более низкого порога (по сравнению с существующим) по предъявляемому критерию применения ЕCXH, на наш взгляд, не в полной мере позволит решить вопрос снижения налоговой нагрузки на сельхозтоваропроизводителей и не будет соответствовать дифференцированному подходу в зависимости от масштабов производства и размеров предприятия. Необходима разработка механизма дифференциации обложения ЕСХН в зависимости от вида экономической деятельности. Специальный режим должен учитывать как особенности растениеводства, так и животноводства в связи с отличиями образования финансового результата деятельности в данных отраслях.

\section{Список использованной литературы}

1. Доржиева И. Ц.-Д. Современное состояние сельского хозяйства Республики Бурятия / И. Ц.-Д. Доржиева, И. Т. Данеева, С. В. Жаргалова // Развитие и размещение производительных сил Республики Бурятия : материалы юбилейн. Междунар. науч.-практ.

\section{Baikal Research Journal}

электронный научный журнал Байкальского государственного университета 
конф. Улан-Удэ, 22 авг. 2014 г. - Улан-Удэ : Изд-во Бурят. гос. с.-х. акад. им. В. Р. Филиппова, 2014. - С. 141-148.

2. Последствия вступления России во Всемирную торговую организацию для региональной экономики / А. П. Киреенко, Д. Ю. Федотов, Л. В. Санина [и др.]. - Иркутск : Изд-во БГУЭП, 2013. - 252 с.

3. Тихонова А. В. Налоговое регулирование аграрного сектора: оценка и проблематика / А. В. Тихонова // Известия Иркутской государственной экономической академии. 2014. - № 6 (98). - C. 25-34. - DOI: 10.17150/1993-3541.2014.24(6).25-34.

4. Налоговая система: современное состояние и перспективы развития: материалы Междунар. науч.-практ. конф. Иркутск, 22-23 апр. 2010 г. / под ред. В. И. Самарухи. Иркутск : Изд-во БГУЭП, 2010. - 218 с.

5. Дашибылова С. В. Задолженность по налогам и сборам отрасли сельского хозяйства в бюджетную систему Российской Федерации / С. В. Дашибылова // Проблемы экономики России и Монголии : сб. науч. тр. - Иркутск : Изд-во БГУЭП, 2013. - С. 201-204.

6. Чупина И. П. Особенности налогообложения в сельском хозяйстве РФ / И. П. Чупина // Аграрный вестник Урала. - 2011. - № 10 (89). — С. 67-69.

7. Старкова О. Я. Налоговое бремя сельскохозяйственных предприятий / О. Я. Старкова // Пермский аграрный вестник. - 2014. - № 3 (7). - С. 70-77.

8. Казьмин А. Г. Налогообложение сельскохозяйственных товаропроизводителей России / А. Г. Казьмин, И. В. Оробинская // Современная экономика: проблемы, тенденции, перспективы. - 2013. - № 9 (2). - С. 56-72.

9. Родионова О. А. Эффективность применения в сельском хозяйстве специальных налоговых режимов / О. А. Родионова, О. Т. Копытина // АПК: Экономика, управление. 2014. - № 1. - С. 50-56.

10. Косинский П. Д. Совершенствование налоговых отношений в агропродовольственном кластере региона / П. Д. Косинский, Н. С. Бондарев, Г. С. Бондарева // Региональная экономика: теория и практика. - 2013. - № 5 (284). - С. 22-29.

11. Шадрина М. А. Порядок определения доли от реализации продукции сельского хозяйства и продуктов ее первичной переработки / М. А. Шадрина // Бухучет в сельском хозяйстве. - 2013. - № 5. - С. 41-48.

12. Степаненко Е. И. Анализ эффективности альтернативных систем налогообложения, применяемых сельскохозяйственными предприятиями / Е. И. Степаненко, И. А. Иванова // Бухучет в сельском хозяйстве. - 2010. - № 4. - С. 35-39.

\section{References}

1. Dorzhiyeva I. Ts.-D., Daneyeva I. T., Zhargalova S. V. Current state of agricultural sector in Republic of Buryatia. Razvitie i razmeshchenie proizvoditel'nykh sil Respubliki Buryatiya. Materialy yubileinoi Mezhdunarodnoi nauchno-prakticheskoi konferentsii. Ulan-Ude, 22 avgusta 2014 g. [Development and placement of production forces in Republic of Buryatia. Materials of Jubilee International Research Conference. Ulan-Ude, August 22, 2014]. Ulan-Ude, Buryat State Agriculture Academy by V. R. Philippov Publ., 2014, pp. 141-148. (In Russian).

2. Kireenko A. P., Fedotov D. Yu., Sanina L. V. et al. Posledstviya vstupleniya Rossii vo Vsemirnuyu torgovuyu organizatsiyu dlya regional'noi ekonomiki [The consequences of Russia's entry into the World Trade Organization for the regional economy]. Irkutsk, Baikal State University of Economics and Law Publ., 2013. 252 p.

3. Tikhonova A. V. Agricultural sector tax regulation: evaluation and problems. Izvestiya Irkutskoy gosudarstvennoy ekonomicheskoy akademii = Bulletin of Irkutsk State Economics Academy, 2014, no. 6 (98), pp. 25-34. DOI: 10.17150/1993-3541.2014.24(6).25-34. (In Russian).

4. Samarukha V. I. (ed.). Nalogovaya sistema: sovremennoe sostoyanie i perspektivy razvitiya [Tax System: Current State and Development Prospects. Irkutsk, Apr. 22-23, 2010]. Irkutsk, Baikal State University of Economics and Law Publ., 2010. 218 p.

5. Dashibylova S. V. Levies liabilities of the agricultural sector in the budget of the Russian Federation. Problemy ekonomiki Rossii i Mongolii [Economic Problems of Russia and Mongolia]. Irkutsk, Baikal State University of Economics and Law Publ., 2013, pp. 201-204. (In Russian).

\section{Baikal Research Journal}


6. Chupina I. P. Features of taxation in the RF agricultural sector. Agrarnyi vestnik Urala = Agrarian Herald of the Urals, 2011, no. 10 (89), pp. 67-69. (In Russian).

7. Starkova О. Я. Tax burden of agricultural enterprises. Permskii agrarnyi vestnik = Perm Agrarian Journal, 2014, no. 3 (7), pp. 70-77. (In Russian).

8. Kazmin A. G., Orobinskaya I. V. Taxation of agricultural producers of Russia. Sovremennaya ekonomika: problemy, tendentsii, perspektivy = Modern Economics: Problems, Trends, Prospects, 2013, no. 9 (2), pp. 56-72. (In Russian).

9. Rodionova O. A., Kopytina O. T. Efficiency of using special tax treatments in the agricultural sector. APK: ekonomika, upravleniye = Agro-Industrial Complex: Economics, Management, 2014, no. 1, pp. 50-56. (In Russian).

10. Kosinsky P. D., Bondarev N. S., Bondareva G. S. Improving tax relations in regional agricultural cluster. Regional'naya ekonomika: teoriya i praktika = Regional Economy: Theory and Practice, 2013, no. 5 (284), pp. 22-29. (In Russian).

11. Shadrina M. A. The procedure of determining the share from sales of agricultural production and products of its primary processing. Bukhuchet $v$ sel'skom khozyaistve = Accounting in Agriculture, 2013, no. 5, pp. 41-48. (In Russian).

12. Stepanenko E. I., Ivanova I. A. Analysis of efficiency of alternative taxation systems used by agricultural businesses. Bukhuchet $v$ sel'skom khozyaistve = Accounting in Agriculture, 2010, no. 4, pp. 35-39. (In Russian).

\section{Информация об авторах}

Доржиева Ирина Цырендашиевна - кандидат экономических наук, доцент, кафедра финансов и кредита, Бурятская государственная сельскохозяйственная академия им. В. Р. Филиппова, 670024, г. Улан-Удэ, ул. Пушкина, 8, e-mail: dolgorma2015@mail.ru.

Гомбожапова Светлана Викторовна - кандидат экономических наук, старший преподаватель, кафедра финансов и кредита, Бурятская государственная сельскохозяйственная академия им. В. Р. Филиппова, 670024, г. Улан-Удэ, ул. Пушкина, 8, e-mail: gsv120882@mail.ru.

Данеева Ирина Тогтохоевна - аспирант, кафедра налогов и таможенного дела, Байкальский государственный университет, 664003, г. Иркутск, ул. Ленина, 11, e-mail: ira-bgsha@mail.ru.

\section{Authors}

Irina Ts. Dorzhiyeva - PhD in Economics, Associate Professor, Chair of Finance and Credit, V. R. Filippov Buryat State Agricultural Academy, 8 Pushkin St., 670024, Ulan-Ude, Russian Federation; e-mail: dolgorma2015@mail.ru.

Svetlana V. Gombozhapova - PhD in Economics., Senior Lecturer, Chair of Finance and Credit, V. R. Filippov Buryat State Agricultural Academy, 8 Pushkin St., 670024, Ulan-Ude, Russian Federation; e-mail: gsv120882@mail.ru.

Irina T. Daneyeva - PhD Student, Chair of Taxes and Customs, Baikal State University, 11 Lenin St., 664003, Irkutsk, Russian Federation; e-mail: ira-bgsha@mail.ru.

\section{Библиографическое описание статьи}

Доржиева И. Ц. Особенности налогообложения сельскохозяйственных товаропроизводителей Республики Бурятия / И. Ц. Доржиева, С. В. Гомбожапова, И. Т. Данеева // Baikal Research Journal. - 2016. — T. 7, № 6. — DOI: 10.17150/2411-6262.2016.7(6).2.

\section{Reference to article}

Dorzhiyeva I. Ts., Gombozhapova S. V., Daneyeva I. T. Taxation features for agricultural commodity Producers in Republic of Buryatia. Baikal Research Journal, 2016, vol. 7, no. 6. DOI: 10.17150/2411-6262.2016.7(6).2. (In Russian).

\section{Baikal Research Journal}

